\title{
LOOKING FOR HORTICULTURAL EFFECTS OF SUPERTHRIVETM ON NEPENTHES
}

\author{
BARRY A. RICE • P.O. Box 72741 • Davis, CA 95617•USA • barry@ sarracenia.com \\ EliZABETH M. SALVIA 2668 Ortiz Avenue • Woodland, CA $95776 \bullet$ USA
}

Keywords: cultivation: Nepenthes, SUPERthrive ${ }^{\mathrm{TM}}$.

\section{Introducing SUPERthrive $\mathrm{TM}^{\mathrm{TM}}$}

SUPERthrive ${ }^{\mathrm{TM}}$ is a mysterious, smelly brown liquid that some carnivorous plant growers say has marvelous horticultural properties. Those who love it feel it does wonders for their plants, while those who laugh at it point at the frenetic but oddly empty claims printed on each bottle (e.g., "Dozens of the world's science miracles in every drop!" "50 Instant BioUsables," "The billions-proven extra life maker for plants.")

Does SUPERthrive ${ }^{\mathrm{TM}}$ work? No carnivorous plant grower has ever published a study documenting its value. All too often, reports are anecdotal stories based upon only a few plants (such as, "It saved my Nepenthes rafflesiana from death!") or in tests for which there was no control group (i.e., there were no comparison plants with no SUPERthrive ${ }^{\mathrm{TM}}$ applied). In this paper we present our investigations into the effects of SUPERthrive ${ }^{\mathrm{TM}}$ (hereafter, ST) upon Nepenthes.

If ST has such amazing effects, they should be easily observed in simple experiments.

\section{Experiment I: Drenched Cuttings}

ST supposedly can improve the success rates of rooting Nepenthes from cuttings. When we root Nepenthes cuttings, our usual method involves cutting a long stem into one-node or twonode segments. The leaf blades are trimmed to 1/3-1/2 their full length, and the cuttings are planted in moist Sphagnum. These cuttings are kept in baggies or terraria in moderate light and in warm conditions. Successful cuttings develop roots within a few months. We incorporated ST into our method to see if it would improve our success rates.

We selected two large plants for this experiment: $N$. ×superba and $N$. alata. The success rate of cuttings from these plants depends upon the quality of the cutting. For example, green stem cuttings usually root successfully, while old woody stem cuttings usually fail. We took sixty cuttings from these plants, and randomly divided them into two groups of thirty cuttings each. Both groups included comparable numbers of green and woody cuttings.

The ST concentrations that growers use for this treatment vary, but one "capful" of ST per liter of purified water is commonly cited. The volume of a "capful" probably depends upon the size of the bottle purchased; our resultant ST concentration was $1.9 \mathrm{ml} \mathrm{l}^{-1}$. After being prepared and potted, the thirty plants in the test group were drenched with the ST solution (i.e., sprayed until all plant surfaces were fully wetted). The liberally applied ST drained from the leaves into the soil mix. The cuttings in the control group were also drenched, but with purified water only.

After 12 weeks, we dug the cuttings out of the rooting medium and examined their root systems (see Table 1). In order to avoid observational bias, the person examining the root systems was not told if the plant had been treated with ST. The overall sizes of the root systems of cuttings were ranked as small, medium and large ( $\mathrm{S}, \mathrm{M}, \mathrm{L}$, respectively). A small ( $\mathrm{S}$ ) root system typically consisted of roots only 5-20 mm long; a medium (M) root system consisted of roots 20$40 \mathrm{~mm}$ long, and large (L) roots systems had roots 40-90 $\mathrm{mm}$ long. Dead cuttings were recorded as "D". The length of each successful cutting's longest root was also measured. 


\begin{tabular}{|c|c|c|c|}
\hline Plant/Group & $\%$ Rooted & Root System Rank1 & Longest $\operatorname{Root}^{2}(\mathrm{~cm})$ \\
\hline \multicolumn{4}{|l|}{ ST group } \\
\hline N. ×superba & $83 \%$ & $4 \mathrm{D}, 4 \mathrm{~S}, 6 \mathrm{M}, 9 \mathrm{~L}$ & $3.5 \pm 1.4$ \\
\hline N. alata & $86 \%$ & $1 \mathrm{D}, 1 \mathrm{~S}, 1 \mathrm{M}, 4 \mathrm{~L}$ & $3.8 \pm 1.0$ \\
\hline All ST plants & $83 \%$ & $5 \mathrm{D}, 5 \mathrm{~S}, 7 \mathrm{M}, 13 \mathrm{~L}$ & $3.6 \pm 1.3$ \\
\hline \multicolumn{4}{|l|}{ Control plants } \\
\hline N. ×superba & $96 \%$ & $1 \mathrm{D}, 3 \mathrm{~S}, 12 \mathrm{M}, 7 \mathrm{~L}$ & $5.4 \pm 2.1$ \\
\hline N. alata & $100 \%$ & $0 \mathrm{D}, 1 \mathrm{~S}, 4 \mathrm{M}, 2 \mathrm{~L}$ & $4.7 \pm 1.9$ \\
\hline All control plants & $97 \%$ & $1 \mathrm{D}, 4 \mathrm{~S}, 16 \mathrm{M}, 9 \mathrm{~L}$ & $5.2 \pm 2.0$ \\
\hline \multicolumn{4}{|c|}{${ }^{1}$ Root system rank indicates overall size (Dead, Small, Medium, Large). See text for details. } \\
\hline
\end{tabular}

Table 1: Results for experiment I (soil drenches on fresh cuttings).

\section{Experiment II: Soaked Cuttings}

Some growers submerge their fresh cuttings in a dilute ST solution for an hour before potting them. Soaking fresh cuttings is wise because it may decrease damage from cavitation (an effect where air is drawn into a freshly cut stem, thus decreasing the ability of the stem to transmit fluids). In our experiment to study the affects of ST on this propagation method, four plants were used as cutting donors (Table 2). From previous experience, we knew that the difficulty of producing successful cuttings from these plants ranged from easy ( $N$. ventricosa), to medium (N. thorelii), to difficult ( $N$. tobaica and $N$. carunculata). Ninety-seven cuttings were prepared for this trial. Half the specimens were soaked in a dilute ST solution $\left(1.0 \mathrm{ml} \mathrm{l}^{-1}\right)$ for $46-60 \mathrm{~min}$ utes while the other half were soaked in purified water. Afterwards, the cuttings were planted in moist Tasmanian Sphagnum and treated as normal cuttings. Thirteen weeks later, the cuttings were carefully exhumed and examined. The presence or absence of roots was recorded.

\begin{tabular}{|l|c|c|}
\hline \multicolumn{2}{|c|}{ Plant/Group } & \# of cuttings \\
\hline ST group & 28 & $46 \%$ \\
$N$. ventricosa & 10 & $40 \%$ \\
N. tobaica & 6 & $100 \%$ \\
N. thorelii & 4 & $0 \%$ \\
N. carunculata & 48 & $48 \%$ \\
\hline All ST plants & & \\
& & \\
\hline Control plants & 30 & $50 \%$ \\
$N$. ventricosa & 11 & $27 \%$ \\
N. tobaica & 5 & $100 \%$ \\
N. thorelii & 3 & $0 \%$ \\
N. carunculata & 49 & $47 \%$ \\
\hline All control plants & & \\
\hline
\end{tabular}

Table 2: Results for experiment II (soak treatment). 
Some growers claim the best way to use ST on Nepenthes is through a weekly or biweekly spray. We tested this claim using twenty-seven plants: 9 N. ×superba, 12 N. alata, 3 N. ventri$\cos a, 1 \mathrm{~N}$. maxima, and $2 \mathrm{~N}$. gracilis. These plants ranged from just-rooted cuttings to young plants a few decimeters tall, and none had had prior exposure to ST. The following measurements were taken for each plant: stem length, number of leaves, number of pitchers, and the total leaf surface area. (The leaf surface area of each plant was approximated as $C \sum w_{i} l_{i}$, where $w_{i}$ and $l_{\mathrm{i}}$ are the leaf width and the leaf length of the $i$ th leaf; since the leaves of all the plants studied were approximately diamond-shaped, the sum was multiplied by the geometrical factor $\mathrm{C}=0.5$. Note that the percent leaf increase is insensitive to the geometrical factor used.) The plants were divided into a test group and a control group with similar size and taxonomic compositions. The two groups were grown side by side in a heated greenhouse, and once per week the test group was sprayed-to-wet with a solution of two drops ST per gallon purified water $\left(0.02 \mathrm{ml} \mathrm{l}^{-1}\right)$, a frequently advised concentration. Some ST drained into the soil of the test plants, as prescribed by ST advocates. The control group was similarly drenched, but with pure water only.

Once per month the placement of the two groups in the greenhouse was switched so any environmental differences would be minimized over the duration of the experiment. After six months, the two groups were inspected, and the plant dimensions listed above were once again recorded (see Table 3).

Analysis

Experiment I: We observed nothing of significance when ST was used in a one-time leaf and soil drench on new cuttings (Table 1). The overall rooting success rate of fresh cuttings was actually lower when ST was used (83\% vs. 97\%), but given the relatively small numbers of plants in the experiment the difference was not large enough to be significant. (Welch's t-test yielded $\mathrm{p}=0.09$.) We observed no differences in overall root system rank, nor were we able to detect differences statistically. The root fibers for the ST plants were shorter $(3.6 \pm 1.3 \mathrm{~cm})$ than those of the control plants $(5.2 \pm 2.0 \mathrm{~cm})$, and this result was statistically significant $(\mathrm{p}=0.0009)$. However, we both noticed that while the root fibers of the ST plants were shorter, the root systems seemed commensurately more bushy so the root systems in both groups were of comparable overall size. No differences between the two groups were observed in the number or size of leaves produced. In summary, there were no important differences from ST, either beneficial or detrimental, although ST may have caused minor root length dwarfing.

Experiment II: The data in Table 2 provide absolutely no evidence that soaking fresh Nepenthes cuttings in ST has any effect, either beneficial or detrimental. A t-test analysis produced $\mathrm{p}=0.92$, supporting this lack of measurable effects.

Experiment III: We examined the data from this experiment for any trends that could be attributed to long-term exposure to ST. The average stem length growth was $16.3 \mathrm{~cm}$ for ST

\begin{tabular}{|l|c|c|c|c|}
\hline $\begin{array}{c}\text { Stem length } \\
\text { change }(\mathbf{c m})\end{array}$ & $\begin{array}{c}\text { \# of pitchers } \\
\text { change }\end{array}$ & $\begin{array}{c}\text { \# of leaves } \\
\text { change }\end{array}$ & \multicolumn{1}{c|}{$\begin{array}{c}\text { Leaf area } \\
\text { change }\left(\mathbf{c m}^{2}\right)\end{array}$} & $\begin{array}{c}\text { Leaf area } \\
\text { change }(\%)\end{array}$ \\
\hline $\begin{array}{c}\text { ST group } \\
16.3 \pm 17.9\end{array}$ & $2.6 \pm 1.3$ & $5.9 \pm 2.6$ & $189 \pm 202$ & $356 \pm 398$ \\
$(1-45)$ & $(0-4)$ & $(1-9)$ & $(1-500)$ & $(2-1500)$ \\
\hline $\begin{array}{c}\text { Control group } \\
19.2 \pm 24.3\end{array}$ & $2.0 \pm 1.5$ & $6.8 \pm 3.5$ & $192 \pm 243$ & $517 \pm 691$ \\
$(-1-77)$ & $(0-5)$ & $(2-14)$ & $(-17-737)$ & $(-33-2200)$ \\
\hline
\end{tabular}

Table 3: Results for experiment III (long term exposure). 
plants (19.2 cm for control plants), and the total new leaf production was 5.9 new leaves for ST plants (6.8 new leaves for control plants). Despite many attempts at binning or categorizing the data, we found no significant differences between the ST and control groups. Statistical analyses (t-tests) of the data in Table 3 supported the lack of significance between the ST and control groups ( $\mathrm{p}=0.3-0.98$ for all categories of data).

\section{Discussion}

Despite several months of research involving 184 cuttings and several species of plants, we were unable to detect any beneficial effects from SUPERthrive ${ }^{\mathrm{TM}}$ on the success rates of our Nepenthes cuttings, or on the growth rate of our established Nepenthes plants. We cannot exclude the possibility that SUPERthrive ${ }^{\mathrm{TM}}$ has subtle effects, but these were not observable in our experiments.

This being the case, why is it that some of the finest Nepenthes horticulturists embrace SUPERthrive $^{\mathrm{TM}}$ with such gusto? It might be that when horticulturists apply SUPERthrive ${ }^{\mathrm{TM}}$, they do so in a way that is beneficial to their plants, and in which the presence of SUPERthrive ${ }^{\mathrm{TM}}$ is irrelevant. For example, when a grower plunges freshly made cuttings into a water bath (as in Experiment II), the harmful effects of cavitation are being abated. During the course of this experiment, we learned that a water soak encourages our cuttings to root, so water soaks without SUPERthrive ${ }^{\mathrm{TM}}$ are now standard practice for us. Similarly, we learned that weekly sprinklings of water (as in Experiment III) improved the growth of our Nepenthes, whether or not SUPERthrive ${ }^{\mathrm{TM}}$ is included in the water.

Nepenthes plants have variable growth rates, and this can confound horticultural experiments. For example, in the population of $N$. xsuperba, we observed a range of growth rates which varied by as much as a factor of 7.7 within the same experimental groups. This variability produced enormous standard deviations in our statistics. They might also fool horticulturists into thinking that a treatment method, which might have no value, is having a large effect.

Acknowledgments: We wish to thank Tim Metcalf and Ernesto Sandoval at the Botanical Conservatory at the University of California (Davis) for graciously providing us materials and greenhouse space for this set of experiments.

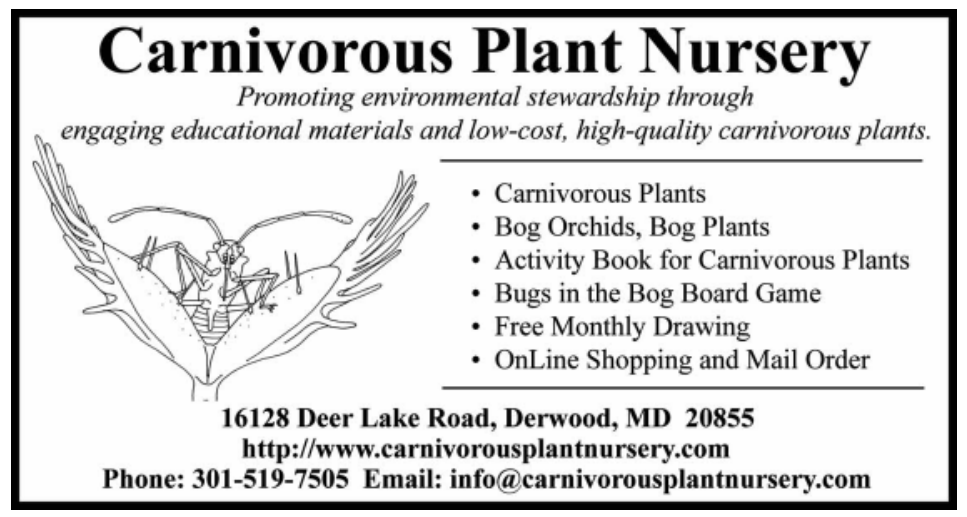

